\title{
Impact of PROTAC Linker Plasticity on the Solution Conformations and Dissociation of the Ternary Complex
}

Dhanushka Weerakoon, ${ }^{1 \dagger}$ Rodrigo J. Carbajo, ${ }^{2 \dagger}$ Leonardo De Maria, ${ }^{1}$ Christian Tyrchan,,${ }^{1}$ and Hongtao Zhao ${ }^{1 *}$

${ }^{1}$ Medicinal Chemistry, Research and Early Development, Respiratory and Immunology (R\&I), BioPharmaceuticals R\&D, AstraZeneca, Gothenburg 43183, Sweden

${ }^{2}$ Chemistry, Oncology R\&D, AstraZeneca, Cambridge CB4 0QA, United Kingdom

†D.W. and R.J.C. contributed equally

*Email: hongtao.zhao@astrazeneca.com 


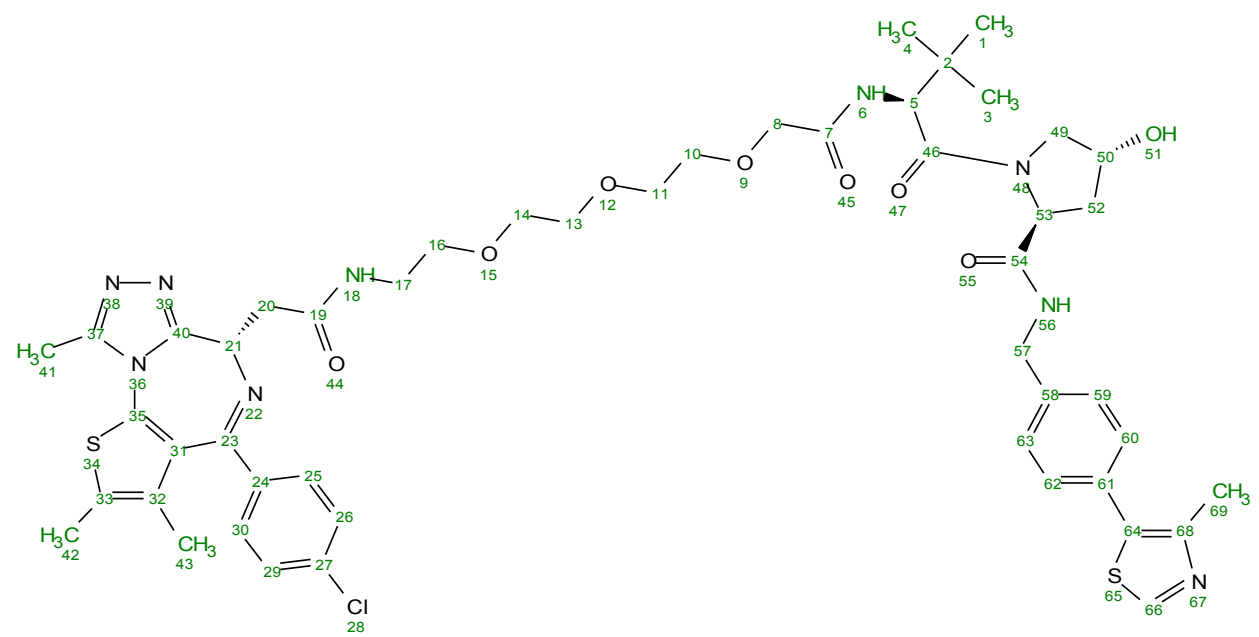

Scheme S1. Atom numbering of MZ1.

Table S1. NOE correlations and interproton distances calculated from analysing F2slices of 2D ROESY of MZ1 in DMSO.

\begin{tabular}{lllll}
\hline Atom 1 & Atom 2 & Normalized integral & Corrected integral & Calculated distance $(\AA)$ \\
\hline $52^{\prime}$ & $52^{\prime \prime}$ & 112.8 & 112.8 & $1.8^{a}$ \\
$1,3,4$ & 56 & 0.40 & 0.40 & 5.0 \\
$1,3,4$ & $59,60,62,63$ & 3.60 & 0.90 & 4.4 \\
$1,3,4$ & 26,29 & 0.32 & 0.16 & 5.8 \\
$1,3,4$ & 57 & 0.27 & 0.27 & 5.3 \\
$1,3,4$ & $11-14$ & 2.93 & 1.47 & 4.0 \\
$1,3,4$ & 16 & 0.68 & 0.34 & 5.1 \\
$1,3,4$ & 17 & 0.86 & 0.43 & 4.9 \\
43 & 21 & 1.07 & 1.07 & 4.2 \\
43 & $10-14$ & 0.85 & 0.43 & 4.9 \\
18 & 21 & 6.90 & 6.90 & 3.1 \\
$25,30,26,29$ & 17 & overlapped & overlapped & N.D. ${ }^{b}$ \\
$25,30,26,29$ & $10-14$ & overlapped & overlapped & N.D. \\
25,30 & 16 & overlapped & overlapped & N.D. \\
$59,60,62,63$ & $10-14$ & overlapped & overlapped & N.D. \\
\hline
\end{tabular}

${ }^{a}$ Reference distance. ${ }^{b}$ Not determined. 
Table S2. NMR assignments of MZ1 in DMSO at $300 \mathrm{~K}$.

\begin{tabular}{lll||lll}
\hline Atom & $\begin{array}{l}{ }^{13} \text { C Chemical } \\
\text { Shift }(\delta \mathrm{ppm})\end{array}$ & $\begin{array}{l}{ }^{1} \mathrm{H} \text { Chemical Shift }(\delta \\
\text { ppm) and } J \text { Coupling }\end{array}$ & $\begin{array}{l}\text { Atom } \\
{ }^{13} \mathrm{C} \text { Chemical } \\
\text { Shift }(\delta \mathrm{ppm})\end{array}$ & $\begin{array}{l}{ }^{1} \mathrm{H} \text { Chemical Shift }(\delta \mathrm{ppm}) \\
\text { and } J \text { Coupling }\end{array}$ \\
\hline 1 & 25.9 & $0.94(\mathrm{~s})$ & 33 & 130.3 & - \\
2 & 35.6 & - & 35 & - & - \\
3 & 25.9 & $0.94(\mathrm{~s})$ & 37 & 149.7 & - \\
4 & 25.9 & $0.94(\mathrm{~s})$ & 40 & 155.0 & - \\
5 & 55.6 & $4.56(\mathrm{~d}, 9.6 \mathrm{~Hz})$ & 41 & 11.0 & $2.59(\mathrm{~s})$ \\
6 & - & $7.42(\mathrm{~d}, 9.6 \mathrm{~Hz})$ & 42 & 12.4 & $2.40(\mathrm{~s})$ \\
7 & 168.5 & - & 43 & 13.8 & $1.62(\mathrm{~s})$ \\
8 & 69.3 & $3.97(\mathrm{~s})$ & 46 & 168.9 & - \\
10 & 70.1 & $3.61(\mathrm{~m})$ & $49^{\prime}$ & 56.3 & $3.60(\mathrm{dd}, 4.1,10.8 \mathrm{~Hz})$ \\
11 & 69.4 & $3.57(\mathrm{~m})$ & $49^{\prime \prime}$ & 56.3 & $3.67(\mathrm{~m})$ \\
13 & 69.4 & $3.57(\mathrm{~m})$ & 50 & 68.6 & $4.35(\mathrm{~m})$ \\
14 & 69.4 & $3.57(\mathrm{~m})$ & 51 & - & $5.15(\mathrm{~d}, 3.3 \mathrm{~Hz})$ \\
16 & 68.9 & $3.43(\mathrm{t}, 5.9 \mathrm{~Hz})$ & $52^{\prime}$ & 37.7 & $1.90(\mathrm{ddd}, 13.0,8.8,4.5 \mathrm{~Hz})$ \\
17 & 38.3 & $3.22(\mathrm{~m})$ & $52^{\prime \prime}$ & 37.7 & $2.05(\mathrm{~m})$ \\
$17 "$ & 38.3 & $3.28(\mathrm{~m})$ & 53 & 58.4 & $4.44(\mathrm{t}, 8.2 \mathrm{~Hz})$ \\
18 & - & $8.26(\mathrm{t}, 5.6 \mathrm{~Hz})$ & 54 & 171.7 & - \\
19 & 169.6 & - & 56 & - & $8.59(\mathrm{t}, 6.0 \mathrm{~Hz})$ \\
20 & 37.3 & $3.21(\mathrm{~m})$ & $57^{\prime}$ & 41.4 & $4.25(\mathrm{dd}, 15.8,5.7 \mathrm{~Hz})$ \\
$20 "$ & 37.3 & $3.26(\mathrm{~m})$ & $57^{\prime \prime}$ & 41.4 & $4.38(\mathrm{dd}, 15.9,6.6 \mathrm{~Hz})$ \\
21 & 53.6 & $4.50(\mathrm{dd}, 8.0,6.1 \mathrm{~Hz})$ & 58 & 139.4 & - \\
23 & 162.9 & - & 59 & 127.8 & $7.39(\mathrm{~s})$ \\
24 & 135.1 & - & 60 & 127.8 & $7.39(\mathrm{~s})$ \\
25 & 129.9 & $7.42(\mathrm{~m})$ & 61 & 131.2 & - \\
26 & 128.2 & $7.47(\mathrm{~m})$ & 62 & 127.8 & $7.39(\mathrm{~s})$ \\
27 & 136.6 & - & 63 & 127.8 & $7.39(\mathrm{~s})$ \\
29 & 128.2 & $7.47(\mathrm{~m})$ & 64 & 127.4 & - \\
30 & 129.9 & $7.42(\mathrm{~m})$ & 66 & 151.1 & 8.95 \\
31 & - & - & 68 & 147.7 & - \\
32 & 130.0 & - & 69 & 15.7 & 2.44 \\
\hline & & & & & \\
\hline
\end{tabular}



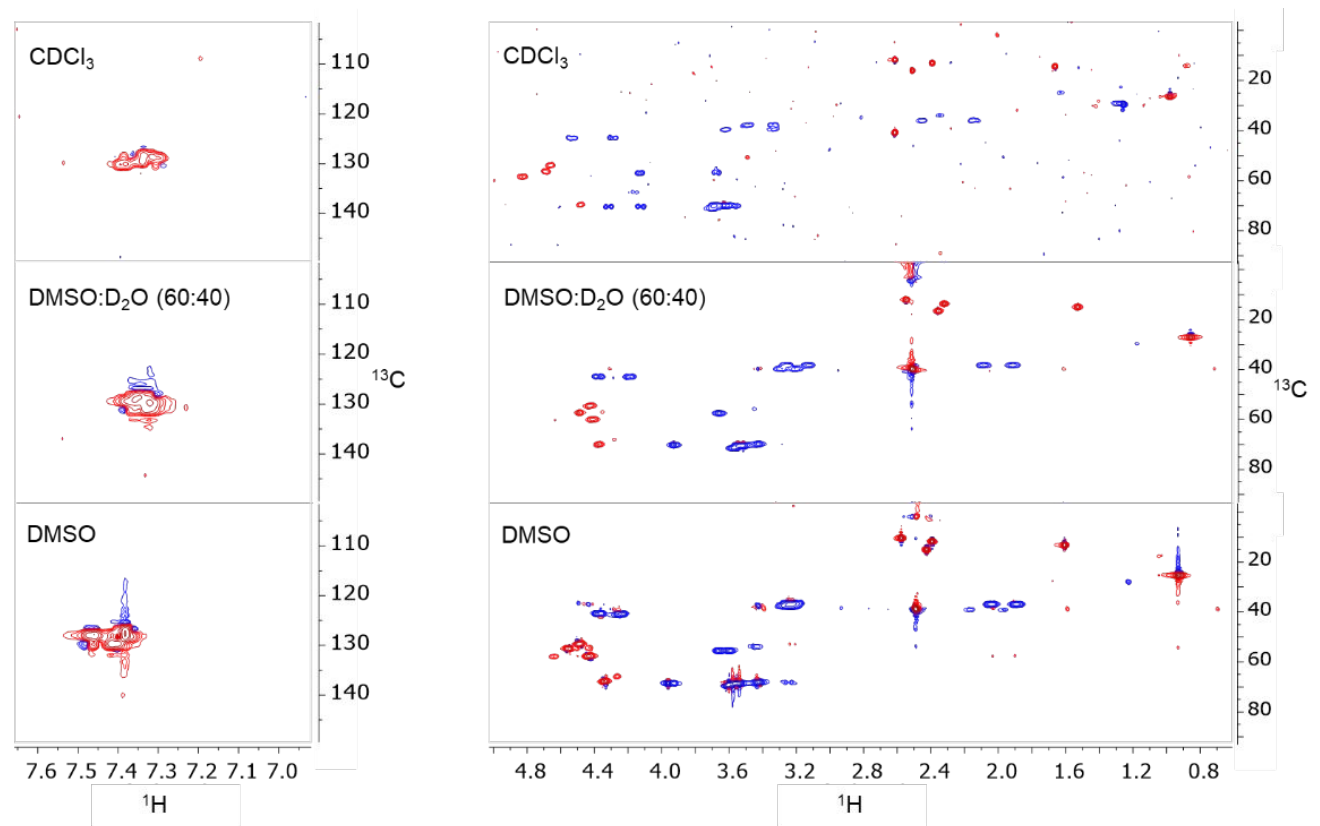

Figure S1. Expansions of ${ }^{1} \mathrm{H}_{-}{ }^{13} \mathrm{C}$ HSQC spectra in DMSO, DMSO: $\mathrm{D}_{2} \mathrm{O}(60: 40)$ and $\mathrm{CDCl}_{3}$.

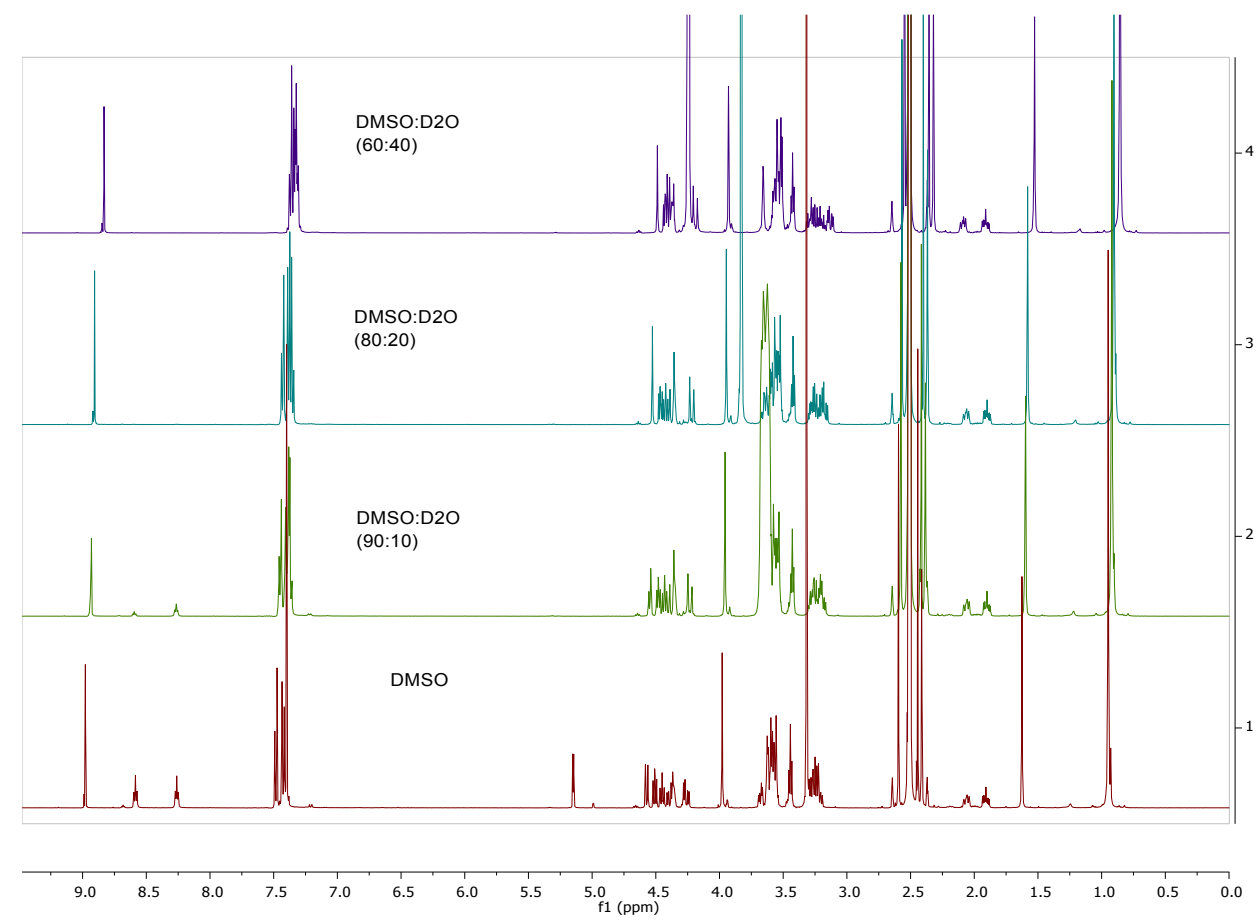

Figure S2. ${ }^{1} \mathrm{H}$ spectra upon addition of incremental amounts of $\mathrm{D}_{2} \mathrm{O}$ to a DMSO solution of MZ1. 


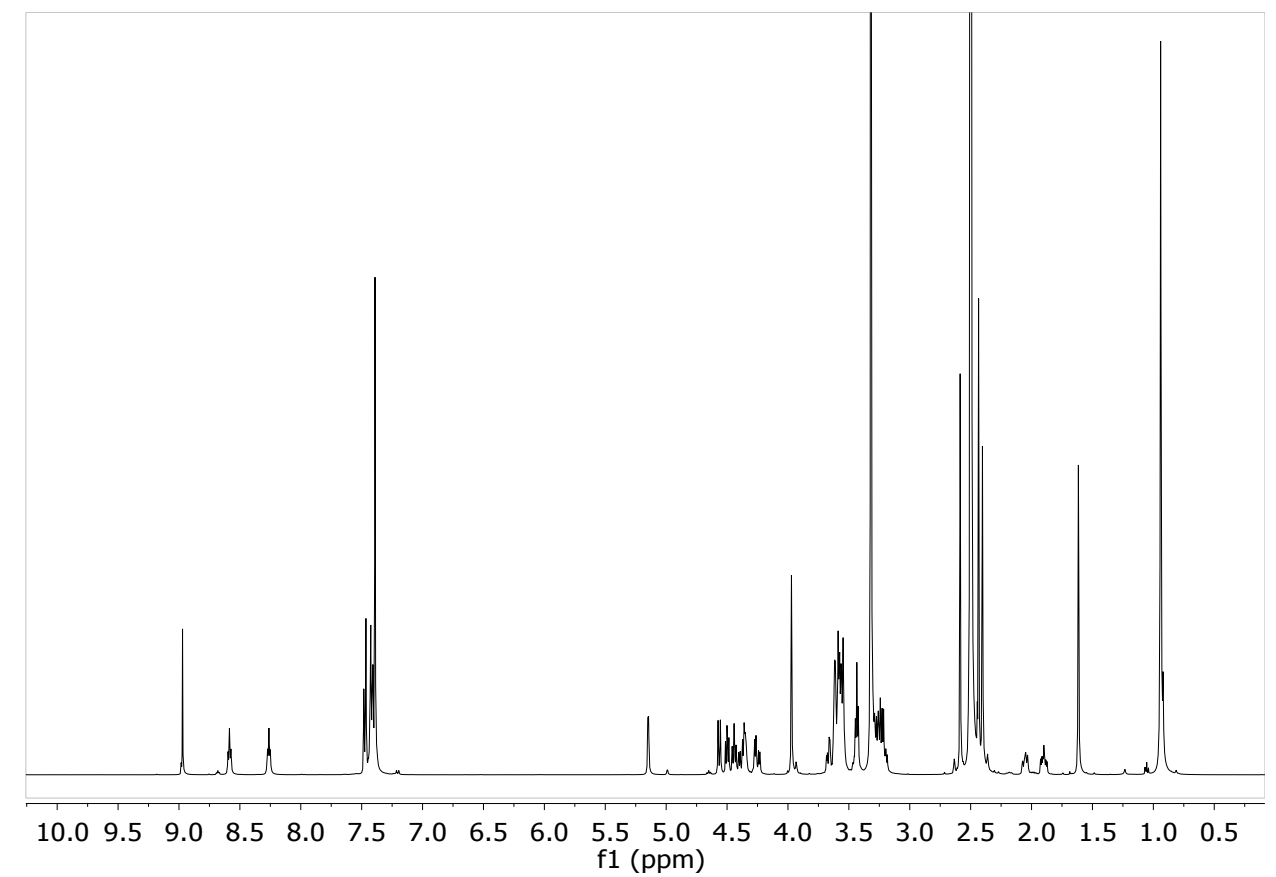

Figure S3. ${ }^{1} \mathrm{H}$ NMR of MZ1 in DMSO.

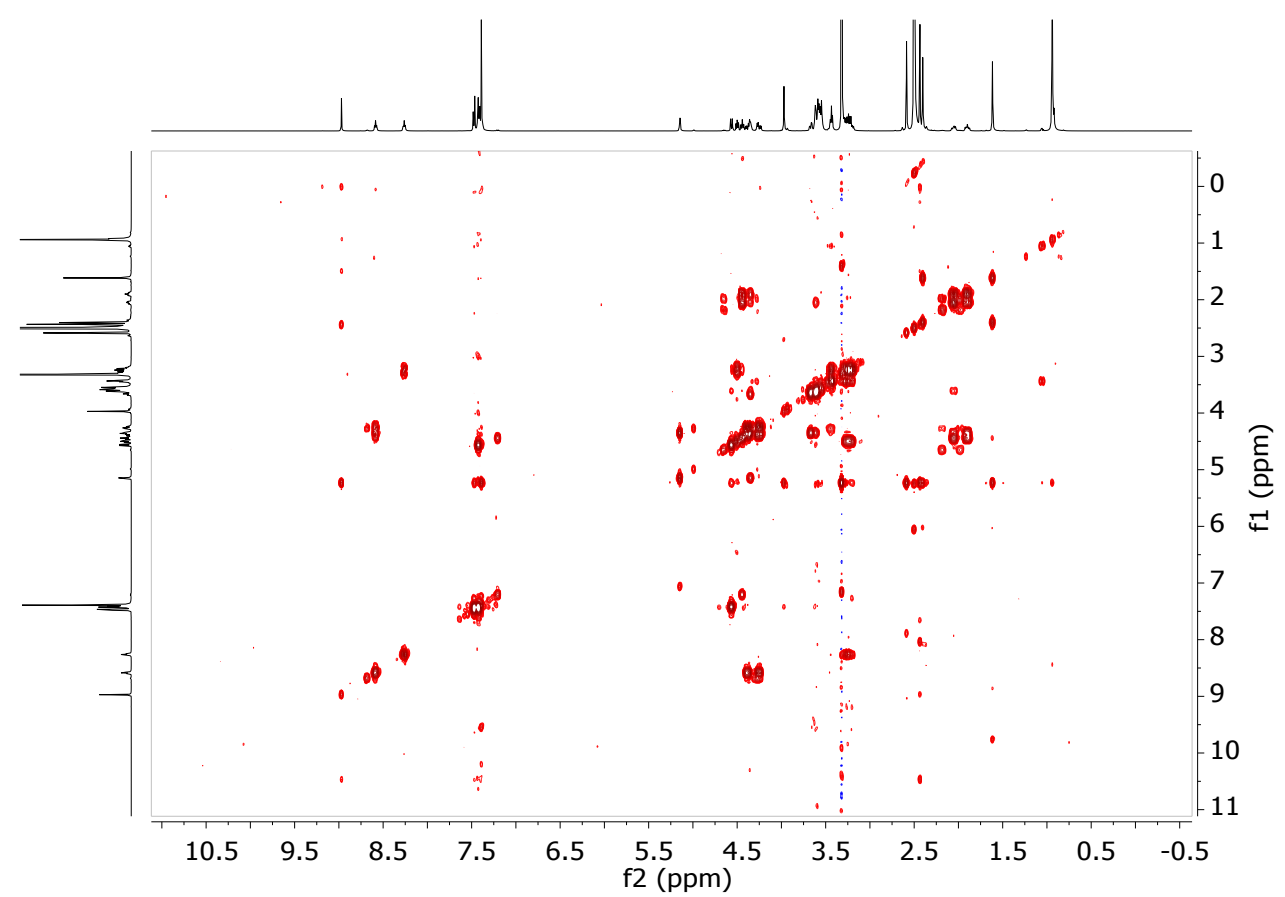

Figure S4. ${ }^{1} \mathrm{H}$ COSY of MZ1 in DMSO. 


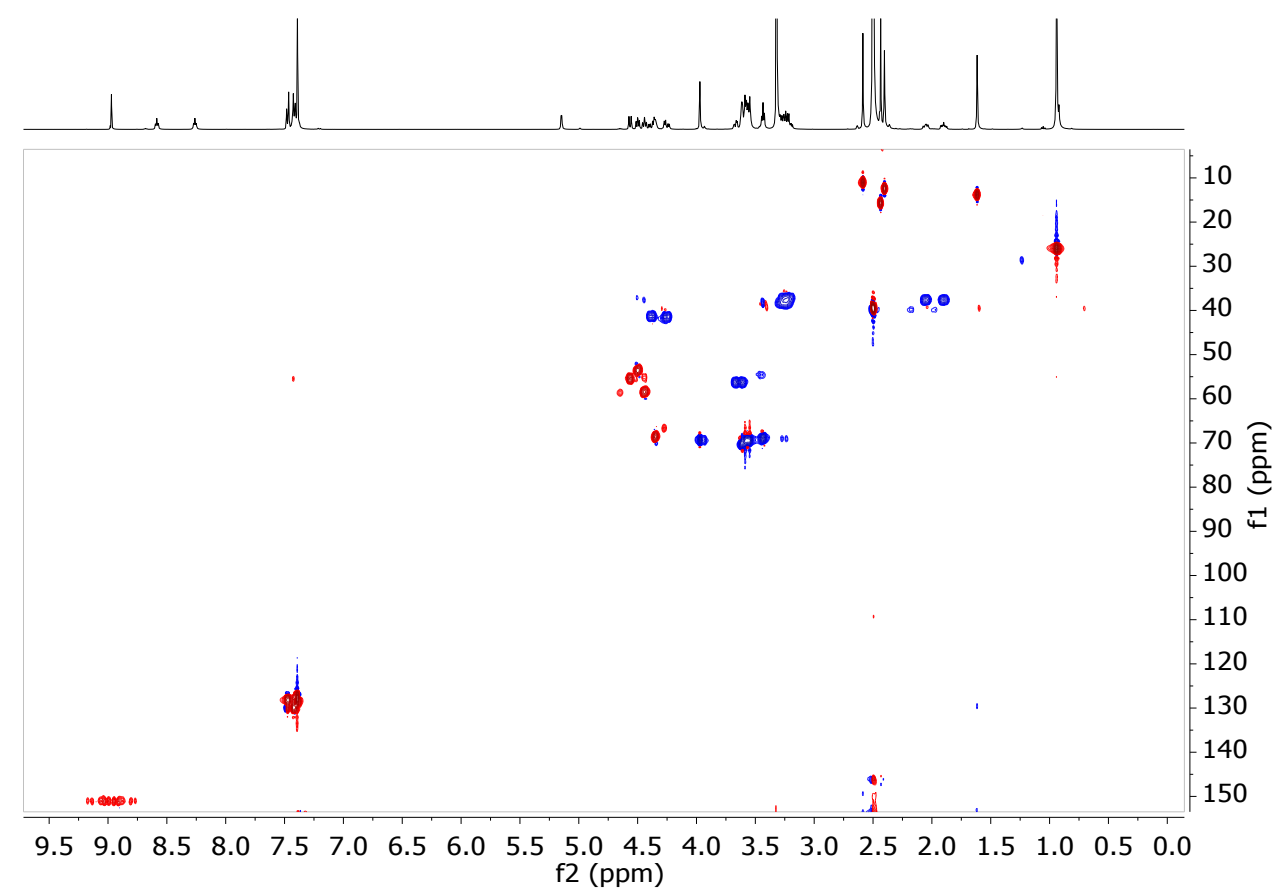

Figure S5. ${ }^{1} \mathrm{H}-{ }^{13} \mathrm{C}$ HSQC of MZ1 in DMSO.

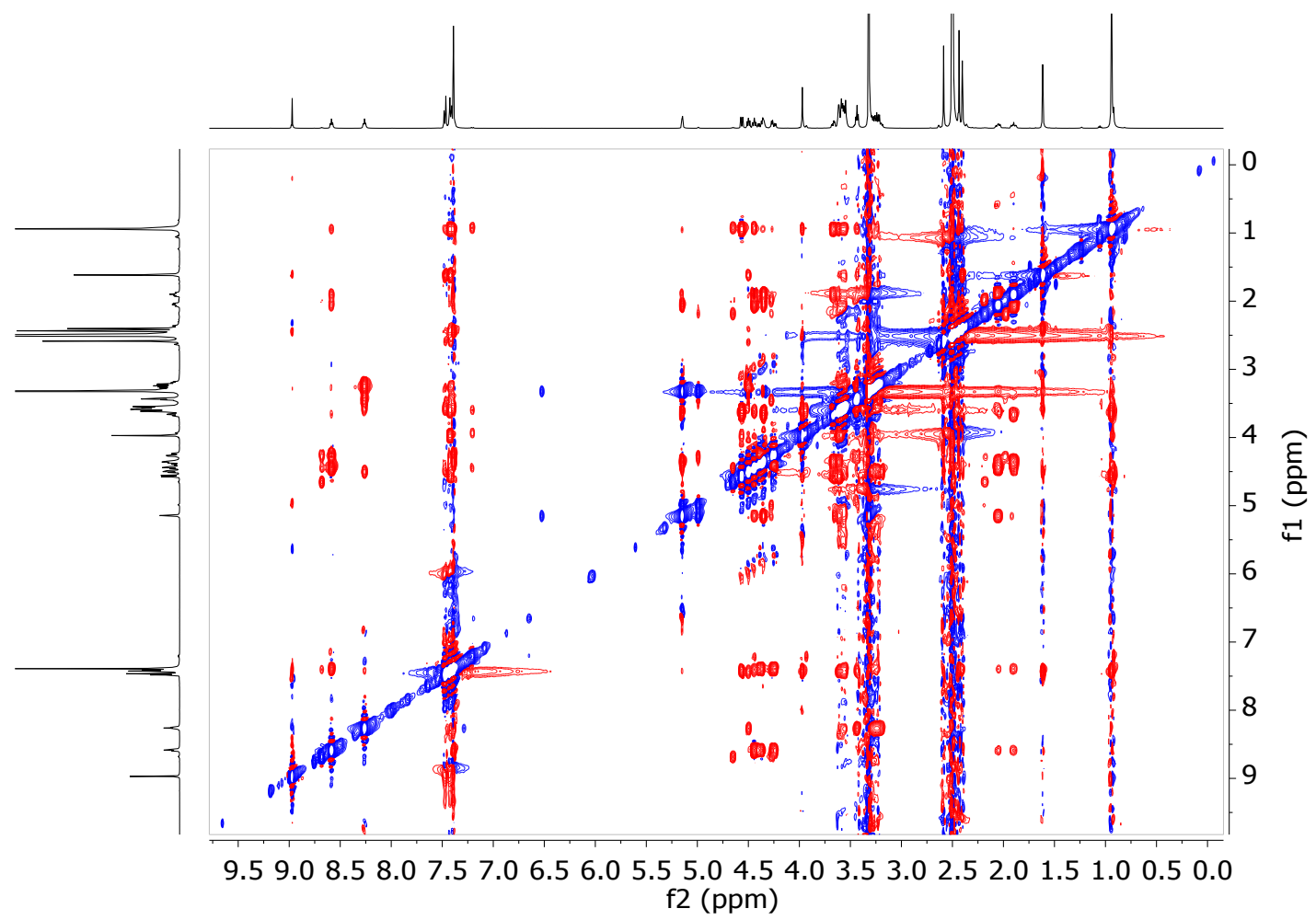

Figure S6. ${ }^{1} \mathrm{H}-{ }^{1} \mathrm{H}$ ROESY of MZ1 in DMSO. 


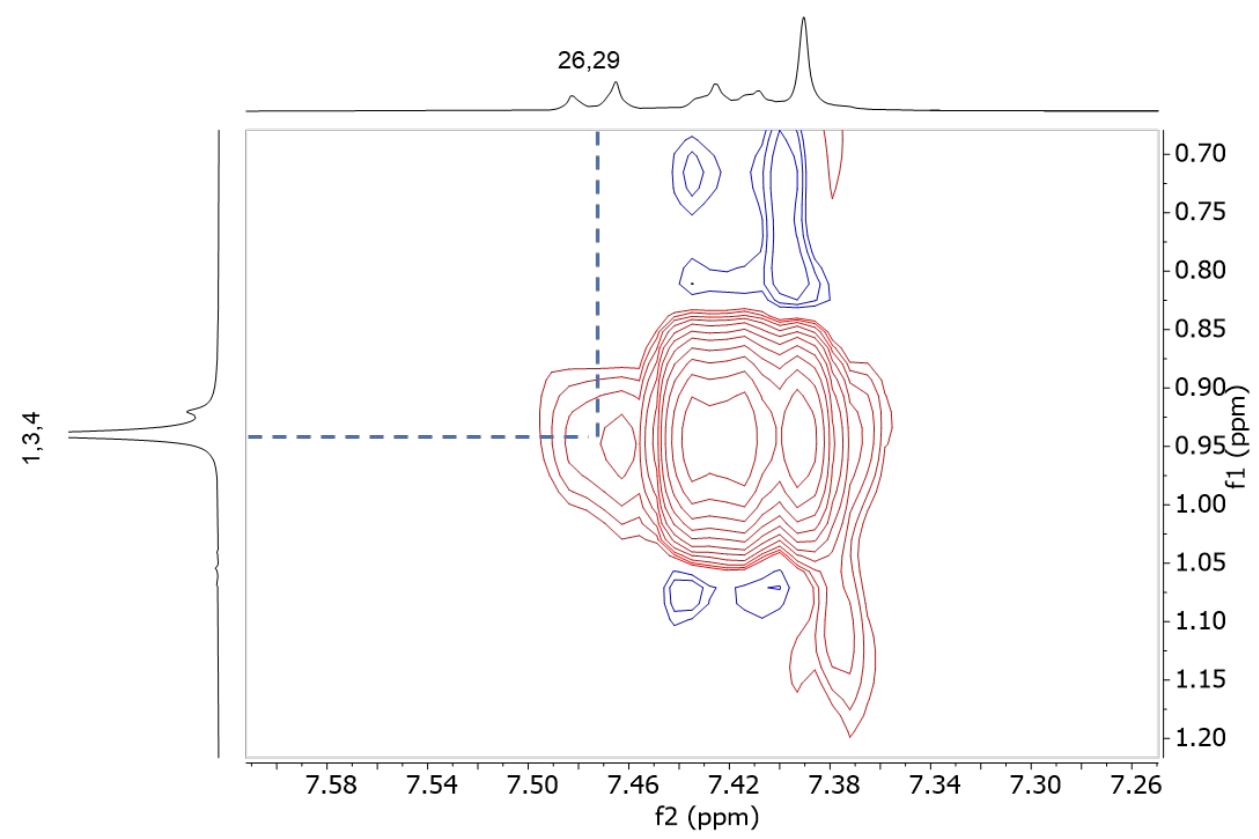

Figure S7. Detail of the ROESY spectrum in DMSO showing the weak cross peak connecting the $t \mathrm{Bu}$ group $(1,3,4)$ and the phenyl protons of the BRD4 ligand $(26,29)$. 


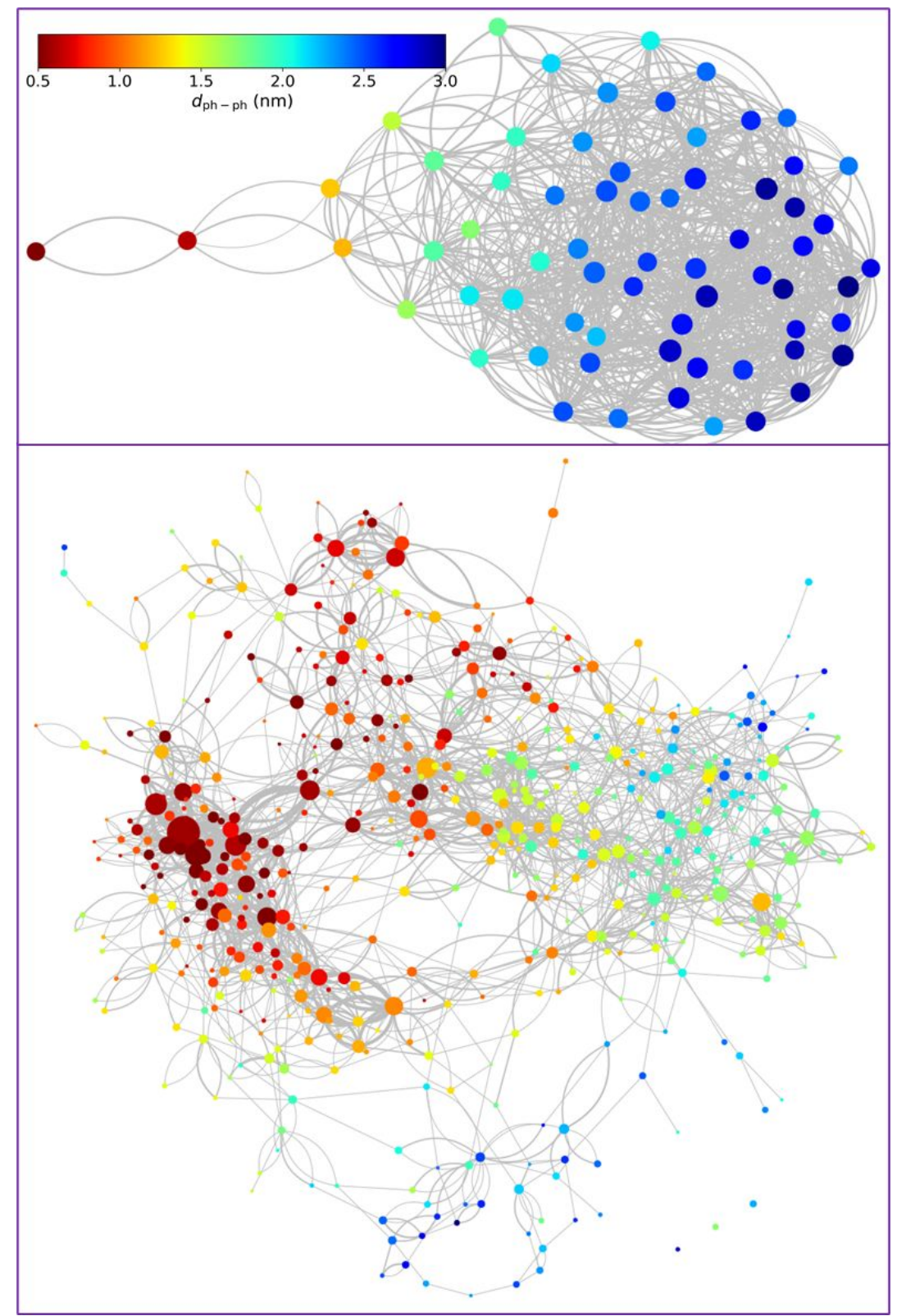

Figure S8. (Top) Conformational transitions of MZ1 in DMSO. Only the 66 nodes with at least 600 snapshots are shown to avoid overcrowding. It highlights that unfolded states colored in blue are highly interconnected while folded states are scarcely linked. (Bottom) Conformational transitions of MZ1 in water. Only the 542 nodes with at least 2 snapshots are shown. 


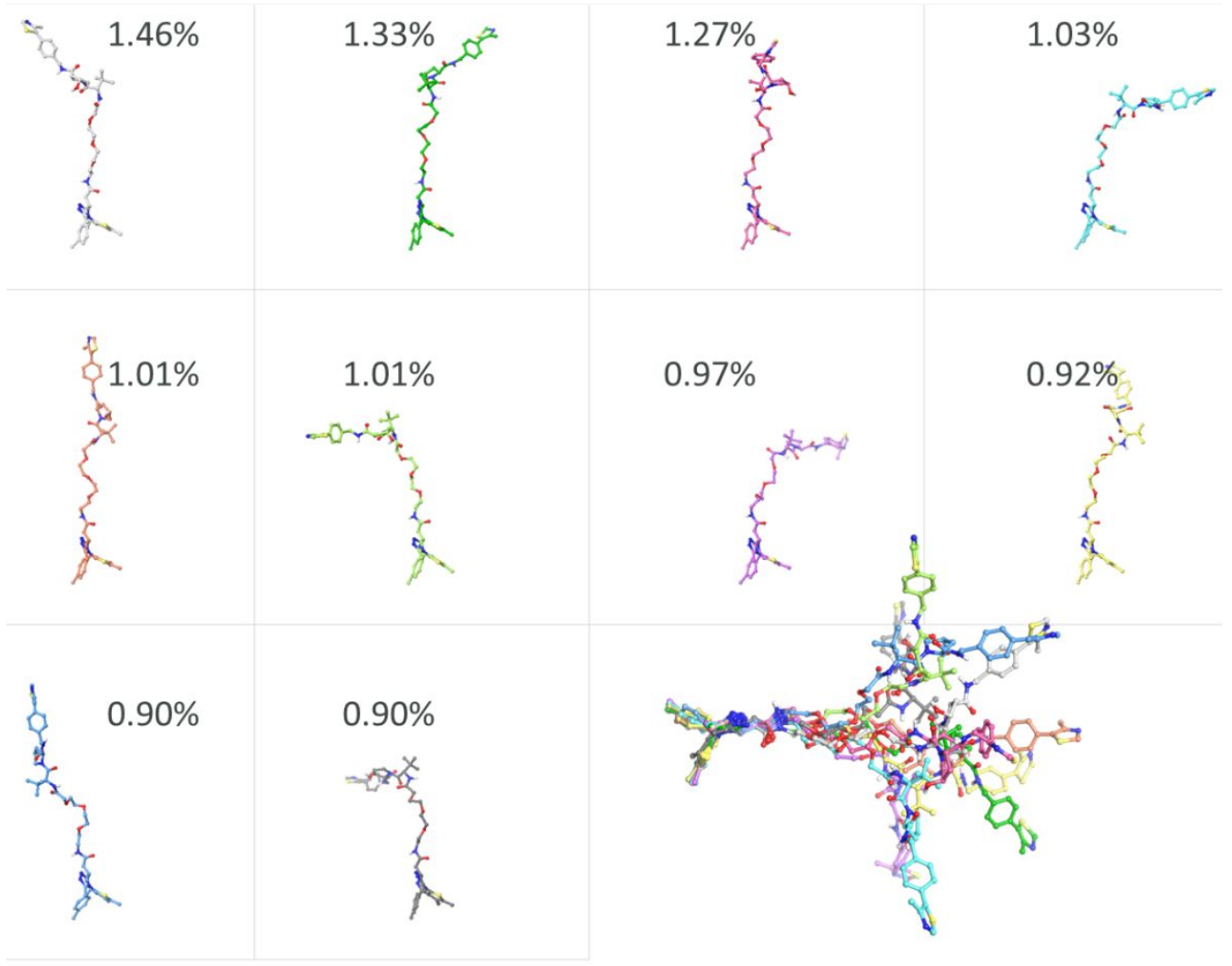

Figure S9. Representative conformations of MZ1 in DMSO each from one of the top 10 largest clusters. The numbers correspond to the population size. The overly of the 10 structures on the BRD4 warhead is shown at the right bottom. 


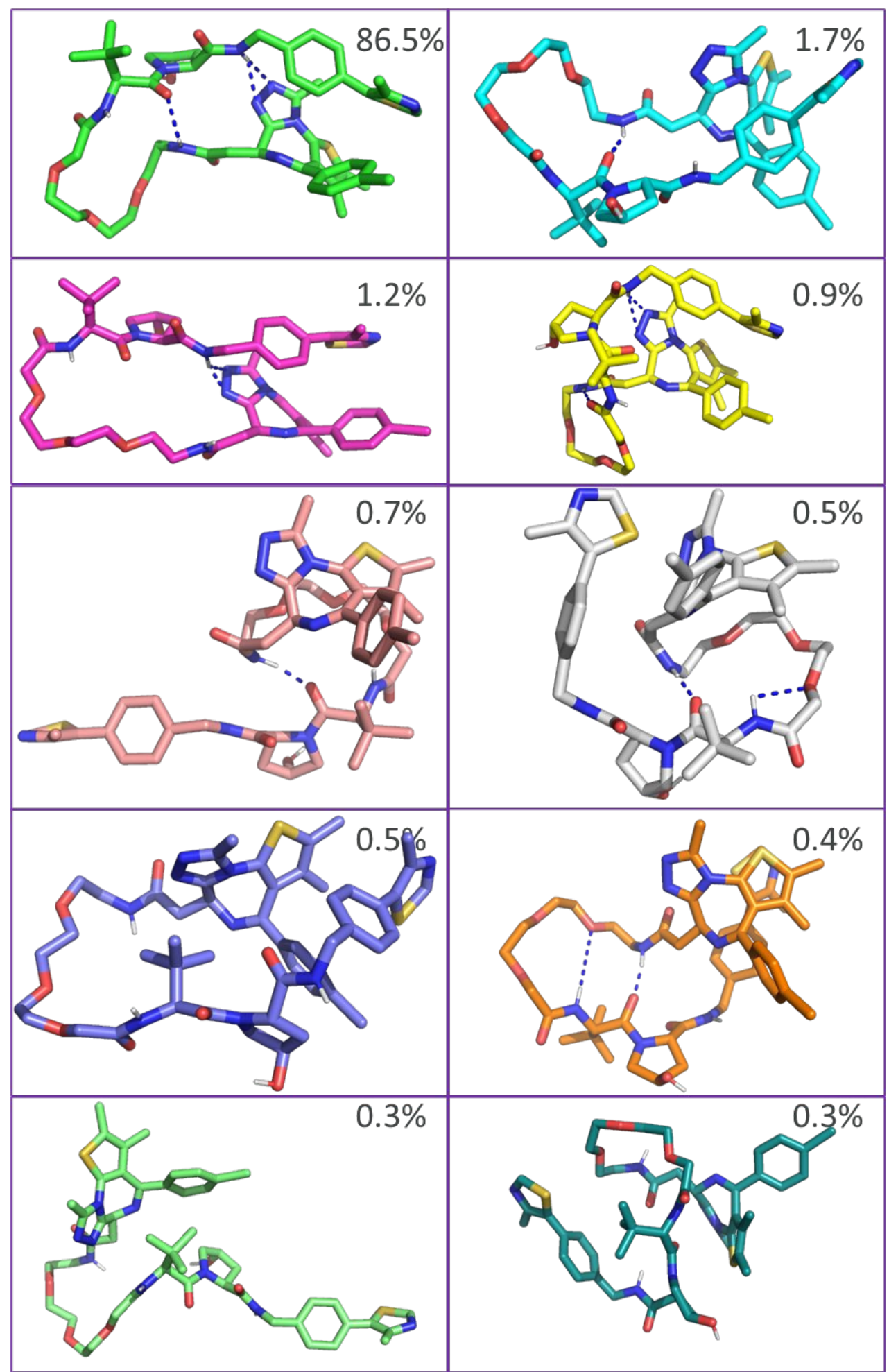

Figure S10. Representative conformations of MZ1 in water each from one of the top 10 largest clusters. The numbers correspond to the population size. 


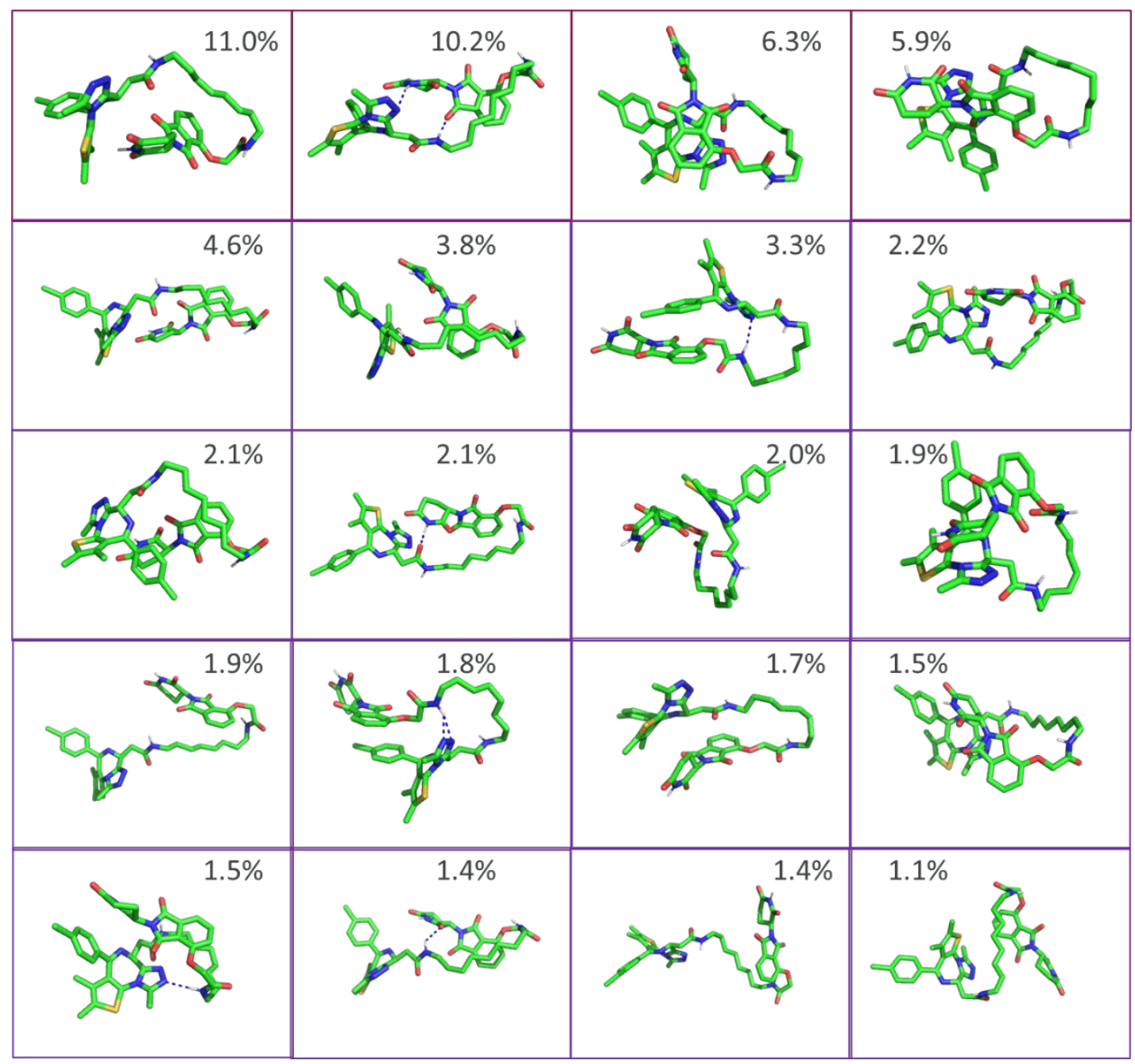

Figure S11. Representative conformations of dBET6 in water each from one of the top 20 largest clusters. The numbers correspond to the population size. 

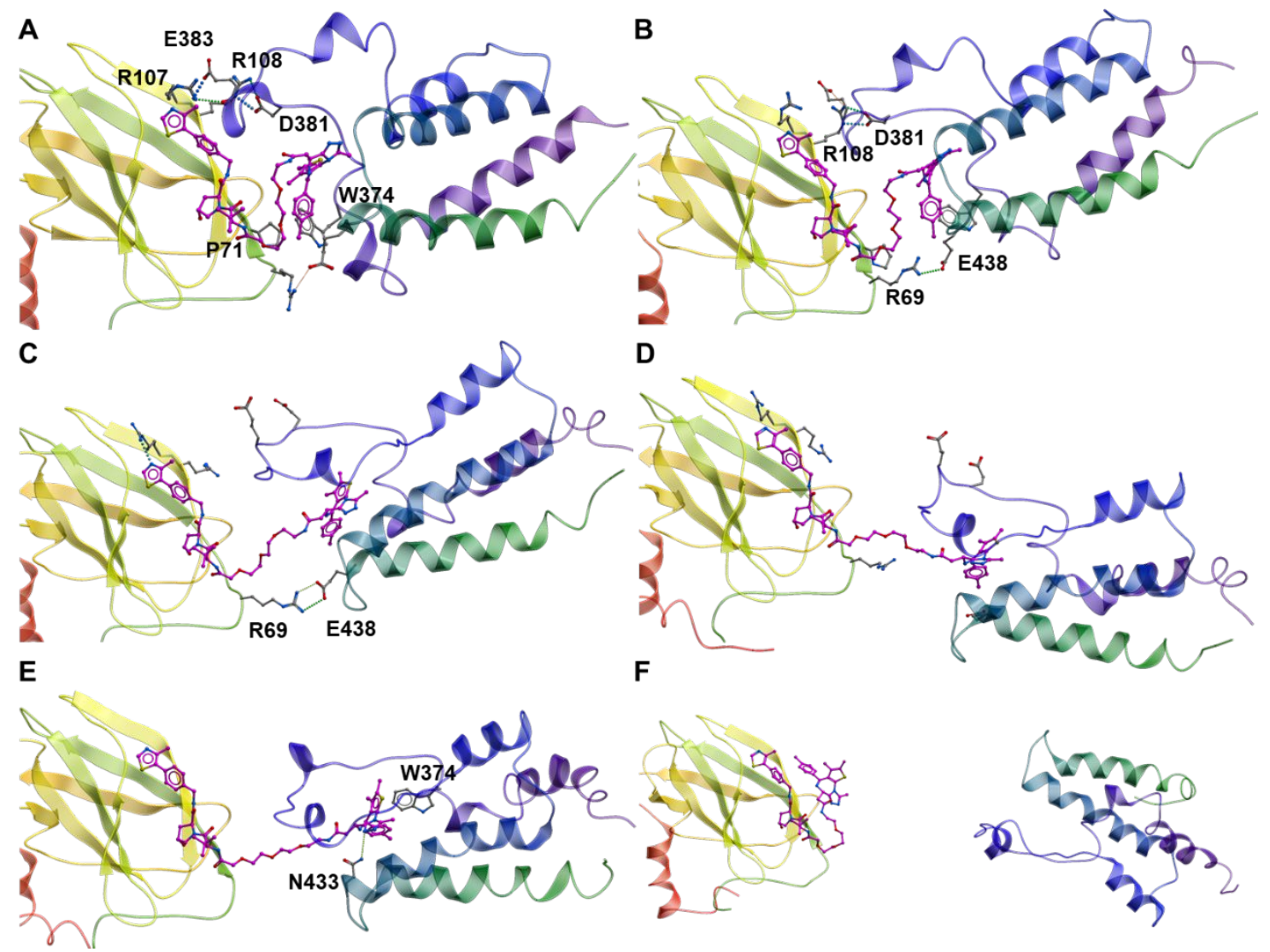

Figure S12. Representative snapshots from the steered MD simulations of the VHL-MZ1BRD4 ternary complex at the extension of 0 (A), 0.4 (B), 0.9 (C), 1.0 (D), 1.5 (E) and $2.5 \mathrm{~nm}$ (F). Structures were aligned on VHL with protein shown in cartoon and MZ1 in stick model. Hydrogen bonds are depicted by dotted lines. 


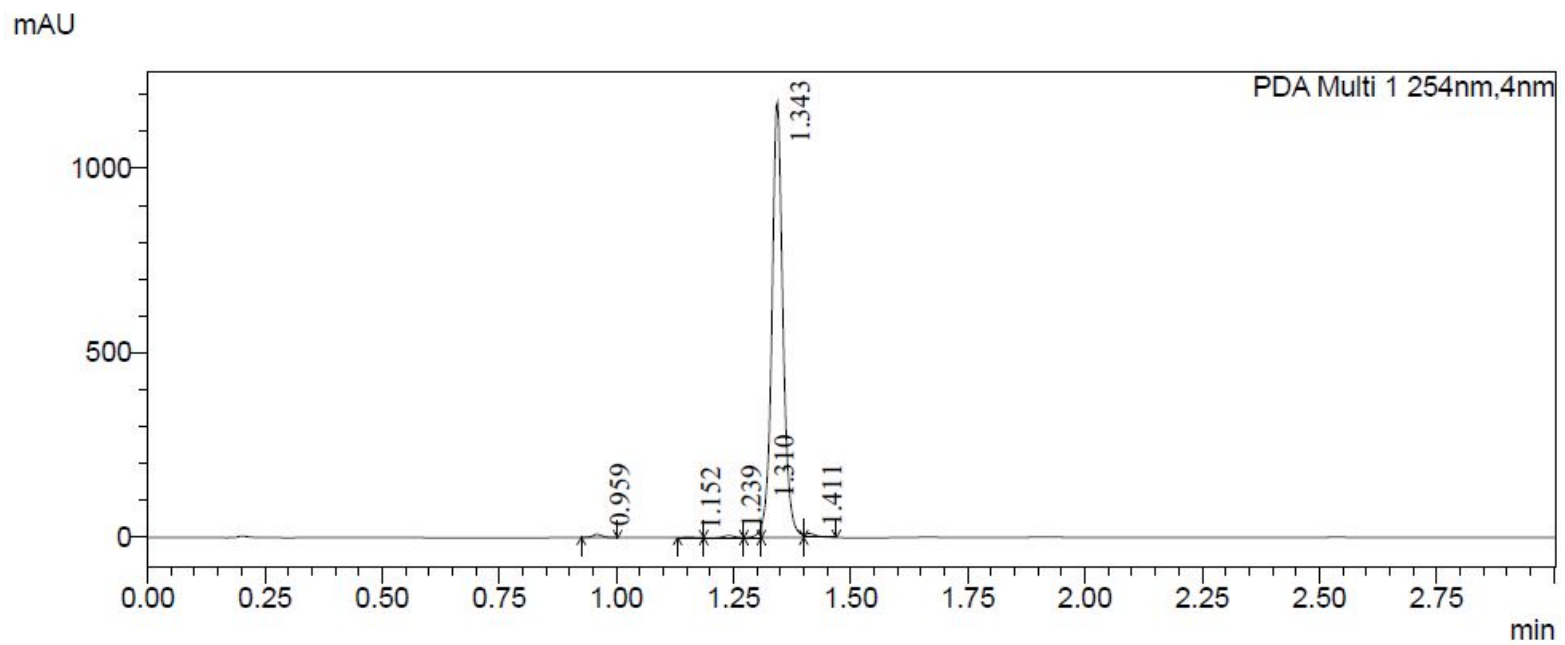

Peak Table

PDA Ch1 254nm

\begin{tabular}{|r|r|r|r|r|r|}
\hline Peak\# & Ret. Time & \multicolumn{1}{c|}{ Height } & Height $\%$ & \multicolumn{1}{c|}{ Area } & \multicolumn{1}{c|}{ Area $\%$} \\
\hline 1 & 0.959 & 8904 & 0.719 & 12168 & 0.613 \\
\hline 2 & 1.152 & 1857 & 0.150 & 2484 & 0.125 \\
\hline 3 & 1.239 & 5643 & 0.456 & 8371 & 0.421 \\
\hline 4 & 1.310 & 31849 & 2.571 & 16579 & 0.835 \\
\hline 5 & 1.343 & 1179912 & 95.255 & 1929984 & 97.147 \\
\hline 6 & 1.411 & 10520 & 0.849 & 17068 & 0.859 \\
\hline Total & & 1238684 & 100.000 & 1986654 & 100.000 \\
\hline
\end{tabular}

Figure S13. LCMS trace of MZ1. 